\title{
Variation in Glucosinolate and Tocopherol Concentrations in a Germplasm Collection of Brassica juncea (L.) Czern. + Coss.
}

Shilpa Gupta ${ }^{1 *}$, Manjeet Kaur Sangha1', Gurpreet Kaur ${ }^{2}$, Amarjeet Kaur Atwal ${ }^{2}$, Prabhjot Kaur ${ }^{2}$, Hitesh Kumar ${ }^{2}$, Shashi Banga ${ }^{2}$ and Surinder Singh Banga $^{2}$

${ }^{1}$ Department of Biochemistry, Punjab Agricultural University, Ludhiana, Punjab- 141004, India

${ }^{2}$ Department of Plant Breeding and Genetics, Punjab Agricultural University, Ludhiana, Punjab-141004, India

\begin{abstract}
Detailed analysis of the leaves and seeds of 97 individual plants of a RIL population derived from the cross of NUDH-YJ-04, a tall and late flowering European juncea having low glucosinolates and RL-1359, a semi dwarf and early flowering Indian juncea having high glucosinolates, grown at a field site revealed a wide variation in total concentrations of seed glucosinolates, leaf glucosinolates, tocopherols and oil. Their contents lied in the ranges of 28.85 to 115.88 $\mu \mathrm{mole} / \mathrm{g}$ seed, $0.82-102.30 \mu \mathrm{mole} / \mathrm{g}$ leaf, 32.29 to $1250 \mathrm{ppm}$ and $34.96-45.00 \%$ respectively. Such variation studies are imperative for map based cloning and QTL mapping of key genes associated with the studied traits which in turn can help us in exploring the genetic view of these biochemicals.
\end{abstract}

Keywords: Glucosinolates; Tocopherols; NIRS (Near Infrared Reflectance Spectroscopy); NMR (Nuclear Magnetic Resonance); Brassica juncea

\section{Introduction}

Modern cultivars and breeding lines of Indian mustard (Brassica juncea (L.) Czern. + Coss.) yield high-quality oil, high-protein seed meal, and are relatively resistant to heat stress, water stress, pod-shattering and fungal diseases. This species has therefore been recognised as a potentially valuable alternative oilseed to rapeseed ( $B$. napus L. and B. campestris L.) in all over world $[1,2]$. However, the usefulness of the crop is still severely limited by the unacceptably high glucosinolate content of the seed meal. There are 3 serious problems associated with breeding and selection for reduced seed glucosinolate content in Brassica species. Firstly, the biochemistry and inheritance of seed glucosinolate content and composition are poorly understood. It is likely that mustard seed glucosinolate content and composition, like the glucosinolate traits of rapeseed [3], are determined by the genotype of the maternal plant rather than by the embryo itself, but the precise nature and extent of this maternal influence is not known. Consequently, it is never entirely clear how to interpret seed analysis data in variable populations. Secondly, seed glucosinolate content is also markedly influenced by a range of environmental and physiological effects such as sulfur nutrition [4], time of sowing [5] and pod position on the plant [6]. Thirdly, until very recently plant breeders have to rely either on rapid but inaccurate and variable 'quick tests', such as glucose assays, or on expensive and time-consuming chromatographic procedures to obtain data on seed glucosinolates [7]. This has severely restricted the number of accurate analyses that can be performed during routine screening of breeding lines. With an awareness of these problems, and with the recent development of an efficient, accurate and reproducible High Performance Liquid Chromatography (HPLC) method for glucosinolate analysis [8], leaf and seed glucosinolate variation between individual plants of $B$. juncea has been recorded along with tocopherols variation.

Glucosinolates are alkyl- $N$-hydroximine sulphate esters with a $\beta$-D-thioglucopyranoside group attached to the hydroximine carbon in Z-configuration to the sulphate group [1-3]. These natural products are biosynthetically produced from amino acids and are present in all plants of the order Capparales and in a few other plants [1,4-6]. Most glucosinolate containing genera are clustered within the families
Capparaceae, Caricaceae and Brassicaceae, the latter including the genus Brassica. More than 140 glucosinolates have been identified up to now, of which about 30 are present in Brassica species $[4,7,8]$. The concentration and composition of the glucosinolates in different plants, but also within a plant (in the seeds, roots or leaves), can vary greatly and also change during plant development [9-12].

Tocopherols have long been known as one of the most potent classes of fat-soluble antioxidants occurring in nature. More recently, beneficial biological roles for natural tocopherols, which are independent of their antioxidant/radical scavenging abilities, have also been suggested, although a definitive function in human health and disease prevention has not been established. Vegetable oils are the most abundant source of naturally occurring tocopherols. Therefore, oilseed crops such as canola and soybean represent the best target for biotechnological costefficient production of tocopherols for use as dietary supplements and food additives. They occur as a family of four derivatives (alpha-, beta-, gamma-and delta-tocopherol; the alpha-derivative is also known as vitamin E), differing in the methylation of the chroman head group. The main biochemical function of the tocopherols is believed to be the protection of polyunsaturated fatty acids against peroxidation [13]. The vitamin E activity of the tocopherols is quite different, alphatocopherol being the most efficient of the four tocopherol-derivatives. However, among them it shows the lowest antioxidant effect in vitro, gamma-tocopherol being the most effective of the four tocopherols [14]. The richest dietary sources of vitamin E are edible oils. Because of their high antioxidative value and health benefits, tocopherols are an interesting goal for improvement of oil quality. For Brassica juncea L.) only very limited information on the variation in tocopherol content is

*Corresponding author: Shilpa Gupta, Department of Biochemistry, Punjab agricultural University, Ludhiana, Punjab-141004, India, E-mail: shilpagupta09@gmail.com

Received March 22, 2012; Accepted October 19, 2012; Published October 23, 2012

Citation: Gupta S, Sangha MK, Kaur G, Atwal AK, Kaur P, et al. (2012) Variation in Glucosinolate and Tocopherol Concentrations in a Germplasm Collection of Brassica juncea (L.) Czern. + Coss. Biochem Anal Biochem 1:121. doi:10.4172/2161-1009.1000121

Copyright: (C) 2012 Gupta S, et al. This is an open-access article distributed under the terms of the Creative Commons Attribution License, which permits unrestricted use, distribution, and reproduction in any medium, provided the original author and source are credited. 
available. In a study on B. napus, Richard et al. [15] reported that, oil contained $358 \mu \mathrm{g} / \mathrm{g}$ of $\gamma$-tocopherol (range of $241-924 \mu \mathrm{g} / \mathrm{g}$ ) and 181 $\mu \mathrm{g} / \mathrm{g}$ of $\alpha$-tocopherol (range of $108-336 \mu \mathrm{g} / \mathrm{g}$ ) and in $B$. juncea it was $379 \mu \mathrm{g} / \mathrm{g}$ (range of $163-777 \mu \mathrm{g} / \mathrm{g}$ ) and $200 \mu \mathrm{g} / \mathrm{g}$ (range of $76-335 \mu \mathrm{g} / \mathrm{g}$ ) respectively and the concentration of $\beta$-tocopherol was relatively low in both species with averages of $25 \mu \mathrm{g} / \mathrm{g}$ (range of $11-64 \mu \mathrm{g} / \mathrm{g}$ ) for $B$. napus and $16 \mu \mathrm{g} / \mathrm{g}$ (range of $4-57 \mu \mathrm{g} / \mathrm{g}$ ) for B. juncea. Goffman et al. and Marwede et al. $[16,17]$ also investigated a collection of 91 species of the family Brassicaceae and observed a wide variability of total tocopherol content in seed oils ranging from $<70 \mathrm{ppm}$ to $2500 \mathrm{ppm}$.

As part of a comprehensive study to provide information on levels and variation of GSs and tocopherols in cruciferous vegetables $(2,3,5$, 19), we have analyzed the GS and tocopherol contents in the leaves and seeds of 97 cultivars.

\section{Materials and Methods}

\section{Plant material}

Seeds of the brown-seeded Indian (RL-1359) and European (NUDH-YJ-04) Brassica juncea were obtained from the Oilseeds section, Department of Plant Breeding and Genetics, Punjab agricultural University, Ludhiana. From the cross of these two mustard lines, a RIL population was developed upto $\mathrm{F}_{6}$ generation. Leaves and seeds were collected from individual $\mathrm{F}_{6}$ plants and assayed for total glucosinolate and tocopherol concentration. NUDH-YJ-04 is a tall and late flowering European juncea having low glucosinolates and RL-1359 is semi dwarf and early flowering Indian juncea having high glucosinolates.

\section{Glucosinolate estimation}

In seeds, glucosinolates have been estimated by NIRS (Near Infrared Reflectance Spectroscopy) following the method of Font et al. [18]. NIRS is a secondary technique which is calibrated against a primary reference method usually a wet laboratory assay. NIRS exploits the fact that many natural products absorbs NIR radiation at specific wavelength (1100-2500 nm) due to absorption of NIR radiation by specific bonds e.g. $\mathrm{N}-\mathrm{H}$ bonds (proteins), $\mathrm{O}-\mathrm{H}$ bonds (moisture/sugars) and $\mathrm{C}-\mathrm{H}$ bonds (organic molecules). Thus a sample's NIR spectrum will be composite of all the absorbance from all the molecular bonds in the sample. Calibration equations are developed by establishing mathematical relationship between NIR spectra and reference values from wet analysis using chemometric techniques. The dust free intact seeds (about $2 \mathrm{~g}$ ) of Brassica juncea were packed in a standard ring cup and then scanned.

In Leaves, glucosinolates have been estimated by colorimetry using the method of Kumar et al. [19]. Glucosinolate estimation is based on the formation of a complex between hydrolytic products of glucosinolates and sodium tetrachloropalladate (II) and this complex is then analyzed colorimetrically. This method is rapid as compared to other colorimetric methods. The amount of glucosinolate-palladium complex formed or the rate of its formation is used to determine the quantity of glucosinolates. Seeds were crushed in methanol and centrifuged at $5000 \mathrm{rpm}$. Sodium tetrachloropalladate was added to the supernatant and glucosinolate content was read at $405 \mathrm{~nm}$ in ELISA reader. Total glucosinolate content was calculated using following regression equations:

$$
\begin{aligned}
& \text { i. Total glucosinolate conc. }(\mu \mathrm{mol} / \mathrm{g})=\left(\mathrm{O}_{\mathrm{D}} \mathrm{D}_{405}-0.046\right) \times 82 \\
& \text { ii. Total glucosinolate conc. }(\mu \mathrm{mol} / \mathrm{g})=\left({\mathrm{O} . \mathrm{D}_{405}}-0.169\right) \times 115.74
\end{aligned}
$$

For expectedly low glucosinolates $\left(\mathrm{O}^{\mathrm{D}} \mathrm{D}_{405}<0.8\right)$ equation (i) is used.

For expectedly high glucosinolates $\left(\mathrm{O}_{\mathrm{D}} \mathrm{D}_{405}>0.8\right)$ equation (ii) is used.

\section{Tocopherol estimation}

Total tocopherol estimation has been done. Seeds were crushed in ethanol following centrifugation at $4000 \mathrm{rpm}$ for $10 \mathrm{~min}$. After adding double distilled water and xylene to supernatant, mixture was again centrifugated at $5000 \mathrm{rpm}$ for $5 \mathrm{~min}$. Xylene layer from the supernatant was carefully pipetted into test tube containing bathophenanthroline reagent, $\mathrm{FeC}_{13}$ reagent and orthophosphoric acid. Absorbance of test, standard and blank was read at $536 \mathrm{~nm}$ against xylene as reference within 30 seconds in UV spectrophotometer (Model 2600). Total tocopherol content was calculated from the standard curve prepared using 2-20 $\mu$ g of $\alpha$-tocopherol in absolute ethanol.

$$
\text { Total tocopherols }=\frac{\text { Conc of std }}{\text { O.Dof std }} \times \text { O.Dof test } \times \frac{\text { Total vol prepared }}{\text { Volof extract taken }} \times
$$

$$
\frac{\text { DilFactor }}{\text { Wt of tissue }} \times \frac{100}{\text { Oilcontent }}
$$

\section{Oil content estimation}

Oil content estimation has been done following the method of Alexander et al. [20]. Nuclear Magnetic Resonance (NMR) is a nondestructive method and a form of radio frequency spectroscopy which provides accurate counts of hydrogen nuclei in liquid oils even in a surrounding matrix of starch, proteins and other macromolecules. The Newport Analyzer (Model MKIIIA) was standardized with standard sample (4 g seeds with a known oil content) and brought the read out value at the desired oil per cent by operating the instrument at the following conditions: Gate width: 1.5 gs Rf level: $100 \mu \mathrm{Amp}$ and integration time: $32 \mathrm{sec}$. Dried seeds of unknown sample $(4 \mathrm{~g})$ were weighed and read the value of the oil content. This gave directly the oil percent in seeds. Oil content of the standard sample was estimated by Soxhlet method.

\section{Results and Discussion}

\section{Seed glucosinolate variation}

Glucosinolates are antinutrional components and the international standards for canola varieties require glucosinolate level to be $<30$ $\mu$ mole/g seed. In the RIL population 95 lines along with two parents were screened for total glucosinolates and the range observed was 28.85 to $115.88 \mu \mathrm{mole} / \mathrm{g}$ tissue, with mean value of $69.39 \pm 0.26$ (Table 1 ). The frequency distribution of glucosinolates in these 95 lines also showed a near normal distribution (Figure 1). Most of the inbred lines were in the range of 41 to $60 \mu \mathrm{mole} / \mathrm{g}$ seed glucosinolate content (21), 45 had occurred in a range of 61-80 $\mu$ mole/g seed and 15 had in range of 81-100 $\mu \mathrm{mole} / \mathrm{g}$ seed while range of 21-40 and 101-120 showed lesser number of lines i.e., 8 and 7 respectively and it was found that there was no line in $0-20 \mu \mathrm{mole} / \mathrm{g}$ seed. Many authors have reported the seed

\begin{tabular}{|l|l|l|l|l|}
\hline Tissue & RL-1359 & NUDH-YJ-04 & Range & Mean \pm CV \\
\hline $\begin{array}{l}\text { Glucoinolate Seeds } \\
(\boldsymbol{\mu} \text { mole/g seed) }\end{array}$ & 102.15 & 53.50 & $28.85-115.88$ & $69.39 \pm 0.26$ \\
\hline $\begin{array}{l}\text { Glucosinolate Leaves } \\
(\boldsymbol{\mu} \text { mole/g leaf) }\end{array}$ & 86.92 & 10.17 & $0.82-102.30$ & $44.18 \pm 0.64$ \\
\hline Tocopherol Seeds (ppm) & 280.76 & 145.87 & $32.29-1250$ & $599.60 \pm 0.62$ \\
\hline Oil seeds (\%) & 39.87 & 40.93 & $34.96-45.00$ & $34.96 \pm 0.73$ \\
\hline
\end{tabular}




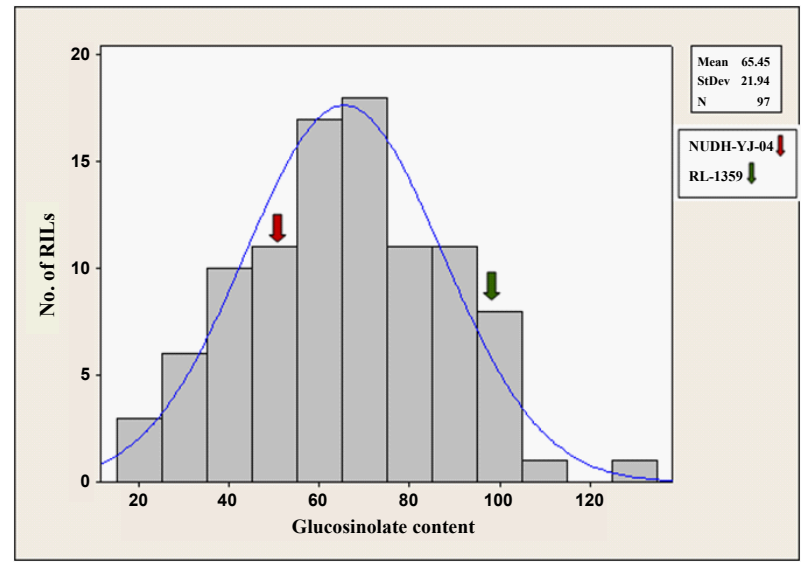

Figure 1: Frequency distribution of glucosinolates in seeds of $B$. juncea individuals.

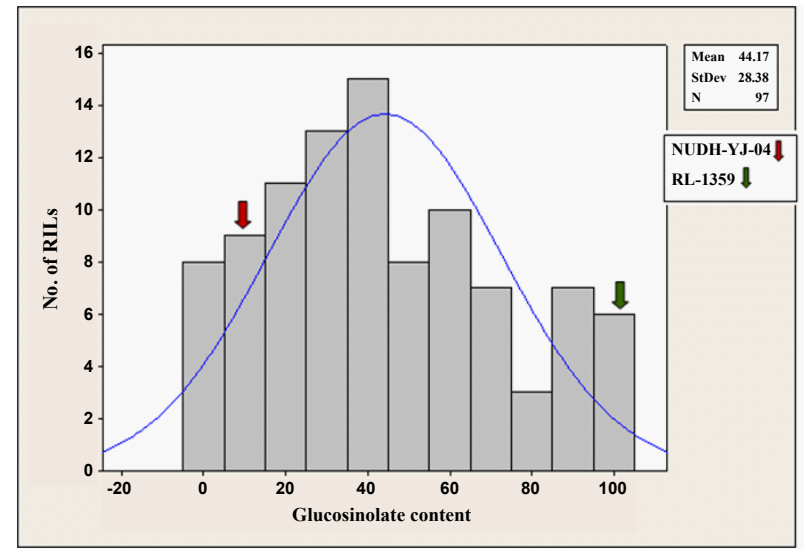

Figure 2: Frequency distribution of glucosinolates in leaves of $B$. juncea individuals.

glucosinolate variation earlier [21,22]. Kumar et al. [19] reported the range of 85-250 $\mu$ mole/g defatted seed meal.

\section{Leaf glucosinolate variation}

In the RIL population range for glucosinolate content in leaves was $0.82-102.30 \mu$ mole/g tissue with mean $\pm \mathrm{CV}$ value of $44.18 \pm 0.64$. RL-1359 had a high glucosinolate content of $86.92 \mu$ mole/g DW leaf and NUDH-YJ-04 had a low glucosinolate content of $10.17 \mu \mathrm{mole} / \mathrm{g}$ DW leaf (Table 1). The frequency distribution of glucosinolate content in these 97 lines showed a discrete distribution (Figure 2). Out of these 97 lines, 29 lines had glucosinolate content in range of 0-25 $\mu$ mole/g DW leaf tissue, 31 lines had 26-50 $\mu$ mole/g DW leaf range, 21 genotypes had 51-75 $\mu$ mole/g DW leaf range, 15 lines had glucosinolates in range of 76-100 $\mu$ mole/g DW leaf with only single individual in 101-125 $\mu$ mole/g DW leaf range. Lewis and Fenwick [23] also reported the variation in glucosinolate content in B. oleracea ranging from $42.1-94.5 \mathrm{mg} / 100 \mathrm{~g}$ FW tissue with mean value of 62.3 $\mathrm{mg} / 100 \mathrm{~g}$. Alemayehu and Becker [24] also found significant variation for glucosinolates in leaves of six inbred lines of B. carinata. Hill et al., Bradshaw and Wilson and Krzymanski et al. [25-27] found significant variation among Brassica lines for glucosinolate content. Remarkable variation in glucosinolate content and profiles from different tissues within one plant may reflect different control mechanism operating on the glucosinolate biosynthetic pathway in different tissues or it may simply result from alterations in substrate availability [28]. Since, glucosinolates are known to arise from amino acid precursors [29], a comparative study of glucosinolate and amino acid profiles in different tissues should prove informative. Dynamic changes of glucosinolate levels in any particular tissue also depend upon regulation of de novo biosynthesis, degradation and mobilization of glucosinolates [30], with the capacity for the de novo synthesis varying according to the type of tissue concerned. Moreover, the chemical structure and glucosinolate concentrations in plants vary considerably, depending on the stage of development, tissue type and environmental conditions [11,31], suggesting a storage function for these compounds which are required at specific stages of development [32]. Wide variation in glucosinolate content among genotypes, also suggest differences in their health promoting properties and the opportunity for enhancement of their levels through genetic manipulation [33].

\section{Seed tocopherol variation}

Tocopherols are important anti-oxidants and variation for its content is reported in table 1. Tocopherols ranged from 32.29 to 1250 ppm with mean $\pm \mathrm{CV}$ value of $550.20 \pm 0.62$. Tocopherol content showed a frequency distribution with both the parents lying in the nearby range (Figure 3). 21 lines had tocopherols range from $0-250$ ppm, 19 genotypes ranged from 251-500, 25 from 501-750, 18 from 7511000 and 14 had range from 1001-1250. Richards et al. and Goffman and Becker $[15,34]$ also reported the variation in total tocopherol content in B. napus that may be due to strong influence of environment due to which tocopherol content differ significantly between cultivars. Large variation in tocopherol content may be due to allelic variation at additional loci. Goffman and Becker and Schultz [34,35] reported the occurrence of multiple allele at a limited number of loci that control the tocopherol content. Variability in tocopherol content suggests the potential health benefits that accrue with consumption are genotype dependent. Seker et al. [36] reported the total tocopherol range of 83.9$173.8 \mathrm{ppm}$ for rapeseed varieties. Przybylski and Mag [37] reported that total tocopherols in crude canola oil ranged from 430-2680 ppm. Tocopherols are most powerful natural fat soluble antioxidant which protect the human body from the free radicals that may lead to ageing process and cause some chronic diseases including cancer, cardiovascular diseases, cataract and retard lipid oxidative rancidity in foods as well as enhance the shelf life of oils containing high content of PUFAs $[38,39]$. Oil extracts with high tocopherol content can be used

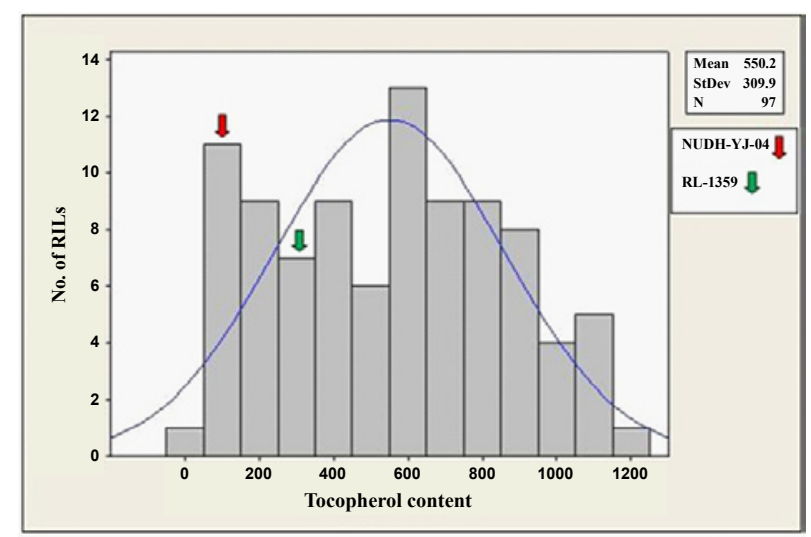

Figure 3: Frequency distribution of tocopherols in seeds of $B$. juncea individuals. 


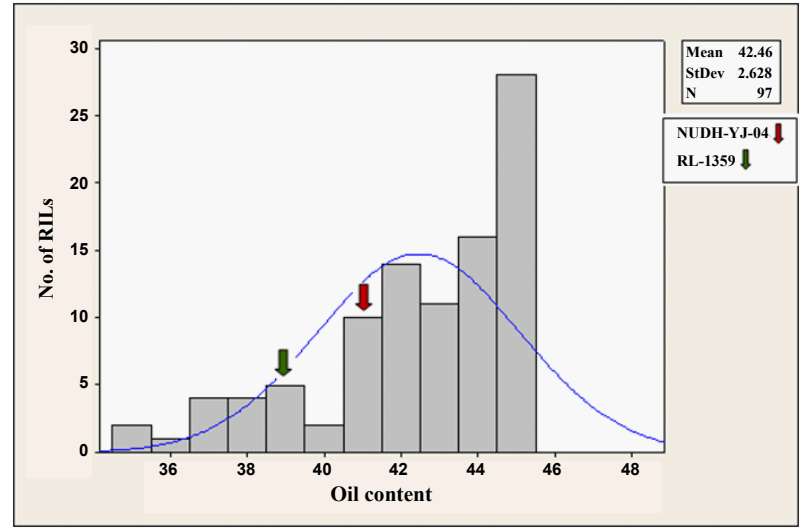

Figure 4: Frequency distribution of oil content in seeds of $B$. juncea individuals.

in application where a high level of antioxidant protection is needed [40]. In rapeseed varieties, total tocopherols markedly increased during maturation stages [41].

\section{Oil content variation}

Seed quality improvement researches in rapeseed-mustard have so far been focused on improving its fatty acid composition to meet the international nutritive norms of oil quality. Oil content ranges from $34.96-45.00 \%$ with mean $\pm \mathrm{CV}$ value of $41.62 \pm 0.73$. Parents showed $39.87 \%$ and $40.93 \%$ oil content in RL-1359 and NUDH-YJ-04 respectively (Table 1). The frequency distribution showed a discrete distribution with more genotypes in $37-45 \%$ range (Figure 4 ). There was no individual in $0-9 \%, 10-18 \%$ and $19-27 \%$ oil content range while just 2 individuals were in $28-36 \%$ and 95 were in $37-45 \%$ range. Si et al. [42] also reported significant variation for seed oil concentration in $B$. napus in the range of 36 to $46 \%$.

The wide range in total glucosinolate concentrations found in this study indicates that there is potential for further reduction of glucosinolate levels by screening different accessions. However, additional sources of naturally occurring or induced genetic variation in total glucosinolate content appear to be essential to achieve the Canola standard for Indian mustard. Also such studies are imperative for map based cloning and QTL mapping of key genes associated with the studied traits which inturn can help us in exploring the genetic view of these biochemicals.

\section{Acknowledgement}

We thank Department of Biotechnology, Government of India for funding this work. The present work was the part of the DBT project entitled "Tagging and marker assisted transfer of low glucosinolate trait in $B$. juncea".

\section{References}

1. Kirk JTO, Oram RN (1978) Mustards as possible oil and protein crops for Australia. J Aust Inst Agri Sci 44: 143-156.

2. Kirk JTO, Oram RN (1981) Isolation of erucic acid-free lines of Brassica juncea: Indian mustard now a potential oilseed crop in Australia. J Aust Inst Agri Sci 47: 51-52.

3. Kondra ZP, Stefansson BR (1970) Inheritance of the major glucosinolates of rapeseed (Brassica napus) meal. Can J Plant Sci 50: 643-647.

4. Josefsson E, Appelqvist LA (1968) Glucosinolates in seed of rape and turnip rape as affected by variety and environment. J Sci Food Agri 19: 564-570.

5. Sang JP, Bluett CA, Elliott BR, Truscott RJW (1986) Effect of time of sowing on oil content, erucic acid and glucosinolate contents in rapeseed (Brassica napus L. cv. Marnoo). Aust J Exp Agri 26: 607-611.
6. Kondra ZP, Downey RK (1970) Glucosinolate content of rapeseed (Brassica napus $L$. and $B$. campestris $L$.) meal as influenced by pod position on the plant Crop Sci 10: 54-56.

7. McGregor DI, Mullin WJ, Fenwick GR (1983) Analytical methodology for determining glucosinolate composition and content. J Assoc Off Anal Chem 66: 825-849.

8. Sang JP, Truscott RJW (1984) Liquid chromatographic determination of glucosinolates in rapeseed as desulfoglucosinolates. J Assoc Off Anal Chem 67: 829-833.

9. Rosa EAS, Heaney RK, Fenwick GR, Portas CAM (1997) Glucosinolates in crop plants. Hort Rev 19

10. Sorensen H, Sorensen S, Bjergegaard C, Michaelsen S (1999) Chromatography and Capillary Electrophoresis in Food Analysis. Royal Society of Chemistry, Cambridge, UK

11. Velasco P, Cartea ME, Gonzalez C, Vilar M, Ordas A (2007) Factors affecting the glucosinolate content of kale (Brassica oleracea acephala group). J Agri Food Chem 55: 955-962.

12. Verkerk R, Schreiner M, Krumbein A, Ciska E, Holst B, et al. (2009) Glucosinolates in Brassica vegetables: The influence of the food supply chain on intake, bioavailability and human health. Mol Nutr Food Res 53: S219.

13. Kamal-Eldin A, Appelqvist LA (1996) The chemistry and antioxidant properties of tocopherols and tocotrienols. Lipids 31: 671-701.

14. Pongracz G, Weiser H, Matzinger D (1995) Tocopherols: antioxidants in nature. Eur J Lipid Sci Technol 97: 90-104.

15. Richard A, Wijesundera C, Salisbury P (2008) Genotype and growing environment effects on the tocopherols and fatty acids of Brassica napus and B. juncea. J Am Oil Chem Soc 85: 159-168.

16. Goffman FD, Velasco L, Becker HC (1999) Tocopherols accumulation in developing seeds and pods of rapeseed (Brassica napus L.). Lipid/Fett 101 400-403.

17. Marwede VA, Schierholt CM, Becker HC (2004) Genotype environment interactions and heritability of tocopherol contents in canola (Crop Breeding, Genetics \& Cytology). Crop Sci 44: 728-731.

18. Font R, del Río M, Fernández-Martínez JM, de Haro A (1998) Determining quality components in Indian mustard by NIRS. Cruciferae Newsletter 20: 6768.

19. Kumar S, Yadav SK, Chauhan JS, Singh AK, Khan NA (2004) Tota glucosinolate estimation by complex formation between glucosinolates and tetrachloropalladate (II) using ELISA reader. J Food Sci Tech 41: 63-65.

20. Alexander DE, Silvela L, Collins FI, Rodgers RC (1967) Analysis of oil content of maize by wide-line NMR. J Am Oil Chem Soc 44: 555-558.

21. Palmer MV, Yeung SP, Sang JP (1987) Glucosinolate content of seedlings, tissue cultures, and regenerant plants of Brassica juncea (Indian mustard). J Agric Food Chem 35: 262-265.

22. Bellostas N, Sorensen AD, Sorensen JC, Sorensen H (2007) Genetic variation and metabolism of glucosinolates. Adv Bot Res 45: 369-415.

23. Lewis J, Fenwick GR (1987) Glucosinolate content of brassica vegetables: Analysis of twenty-four cultivars of calabrese (green sprouting broccoli, Brassica oleracea L. var. botrytis subvar. cymosa Lam.) Food Chem 25: 259268.

24. Alemayehu N, Becker H (2005) Quantitative genetic analysis of tota glucosinolate, oil and protein contents in Ethiopian mustard (Brassica carinata A. Braun). Eth J Sci 28: 141-150.

25. Hill CB, Williams PH, Carlson DG, Tookey HL (1987) Variation in Glucosinolates in Oriental Brassica Vegetables. J Amer Soc Hort Sci 112: 309-313.

26. Bradshaw JE, Wilson RN (1998) Inbred line versus F1 hybrid breeding in Swedes (Brassica napus L. var. Napobrassica Peterm). Ann Appl Biol 123 657-665.

27. Krzymanski J, Pietka T, Krotka K (1994) Combining ability and heterosis in diallel crosses of double low winter oilseed rape II: F1 and F2 generations. Oilseed Crops 15: 21-32.

28. Sang JP, Mrncsrnron IR, Johnstone PK, Truscott RJW (1984) Glucosinolate 
Citation: Gupta S, Sangha MK, Kaur G, Atwal AK, Kaur P, et al. (2012) Variation in Glucosinolate and Tocopherol Concentrations in a Germplasm Collection of Brassica juncea (L.) Czern. + Coss. Biochem Anal Biochem 1:121. doi:10.4172/2161-1009.1000121

Page 5 of 5

profiles in the seed, root and leaf tissue of cabbage, mustard, rapeseed, radish and swede. Can J Plant Sci 64: 77-93.

29. Kutacek M, Prochazka Z, Veres K (1962) Biogenesis of glucobrassicin, the in vitro precursor of ascorbigen. Nature 194: 393-394.

30. Chen S, Andreasson E (2001) Update on glucosinolate metabolism and transport. Plant Physiol Biochem 39: 743-758.

31. Barbieri G, Pernice R, Maggio A, De Pascale S, Fogliano V (2008) Glucosinolates profile of Brassica rapa L. subsp. Sylvestris L. Janch. var. esculenta. Food Chem 107: 1687-1691.

32. Clossais-Besnard N, Larher F (1991) Physiological role of glucosinolates in brassica napus. Concentration and distribution pattern of glucosinolates among plant organs during a complete life cycle. J Sci Food Agric 56: 25-38.

33. Kushad MM, Brown AF, Kurilich AC, Juvik JA, Klein BP, et al. (1999) Variation of glucosinolates in vegetable crops of Brassica oleracea. J Agric Food Chem 47: 1541-1548.

34. Goffman FD, Becker HC (2001) Diallel analysis for tocopherol contents in seeds of rapeseed. Crop Sci 41: 1072-1079.

35. Schultz G (1990) Biosynthesis of a-tocopherol in chloroplasts of higher plants. Fat Sci Tech 92: 86-91.

36. Seker M, Gul MK, Ipek M, Toplu C, Kaleci N (2008) Screening and comparing tocopherols in the rapeseed (Brassica napus L.) and olive (Olea europaea L.) varieties using high-performance liquid chromatography. Int J Food Sci Nutr 59: 483-490.

37. Przybylski R, Mag T (2002) Vegetable oils in food technology: Composition, properties and uses: Canola/rapeseed oil. Blackwell Publishing Ltd, Oxford.

38. Kinsella JE, Frankel E, German B, Kanner J (1993) Possible mechanisms for the protective role of antioxidants in wine and plant foods. Food Technol 47: 85-89.

39. Lai LS, Chou ST, Chao WW (2001) Studies on the antioxidative activities of Hsian-tsao (Mesona Procumbens Hemsl) leaf gum. J Agri Food Chem 49: 963968

40. Demurin Y, Koric D, Karlovic D (1996) Genetic variability of tocopherol composition in sunflower seeds as a basis of breeding for improved oil quality. Plant Breed 115: 33-36.

41. El-Shami SM, Hassanein MMM, El-Mallah MH (2001) Studies on changes in lipid profiles of new varieties of rape during seed maturation. Grasas y Aceites 52: 94-103.

42. Si P, Mailer RJ, Galwey N, Turner DW (2003) Influence of genotype and environment on oil and protein concentrations of canola (Brassica napus L.) grown across southern Australia. Aust J Agri Res 54: 397-407. 